\title{
O APELO DIVISIONAL DA ESTRUTURAÇÃO HÍBRIDA E MULTICAMPI DOS INSTITUTOS FEDERAIS
}

\author{
F. C. M. FERNANDES \\ Professor do Instituto Federal do Rio Grande do Norte \\ Doutor em Ciências da Educação, na especialidade de Organização e Administração Escolar \\ E-mail: francisco.mariz@ifrn.edu.br.
}

Artigo submetido em maio/2016 e aceito em junho/2016

DOI: $10.15628 /$ holos.2016.4529

\section{RESUMO}

A natureza de subunidades organizacionais dos campi, com personalidade jurídica e unidade de gestão próprias, e da reitoria, juridicamente detentora central da identidade institucional, aproxima, teoricamente, a imagem multicampi da organização educativa Instituto Federal da modelagem de Estrutura Divisionalizada conceituada por Mintzberg (1995). Essa forma organizacional parece caracterizar-se como aquela que melhor viabiliza a coordenação regular do funcionamento de um elevado número de campi pelo órgão executivo (reitoria) do Instituto Federal, com o recurso ao princípio da descentralização de poderes e delegação de competência, do reitor para os diretoresgerais dos campi. Soma-se à conjuntura, a condição de que cada campus tem sua própria conformação administrativa e acadêmica de ensino, pesquisa e extensão, ou seja, uma estrutura com todos os componentes básicos da organização, do vértice estratégico no topo ao centro operacional na base.

PALAVRAS-CHAVE: Autonomia; Estrutura Divisionalizada; Instituto Federal; Multicampi; Organização.

\section{THE DIVISIONAL APPEAL OF HYBRID STRUCTURE AND MULTICAMPI OF THE FEDERAL INSTITUTES}

\begin{abstract}
The nature of organizational subunits campuses, with legal personality and own management unit, and the rectory, juridically central holder of institutional identity, approaches theoretically Federal Institute educational organization multicampi image of the divisional structure modeling conceptualized by Mintzberg (1995).

This organizational form seems to be characterized as one which best enables the regular coordination of the operation of a large number of campuses by the
\end{abstract}

executive body (rectory) of the Federal Institute, referring to the principle of decentralization of powers and delegation of competence, from the rector to the directors of the campuses. Added to the environment, the condition that each campus has its own administrative and academic conformation of teaching, research and extension, i.e., a structure with all the basic components

KEYWORDS: Autonomy; Divisional Structure; Federal Institute; Multicampi; Organization. 


\section{ALGUMAS CONSIDERAÇÕES SOBRE PRINCÍPIOS DA ADMINISTRAÇÃO}

No estudo das organizações, não se pode deixar de destacar o início do século XX, em função dos trabalhos do engenheiro Frederick W. Taylor que se tornou o expoente da escola da administração científica quando publicou, em 1911, a obra "The Principles of Scientific Management" (TAYLOR, 1985). Em seguimento, no ano de 1916, fortalecem-se as bases da Teoria Clássica, vinculadas ao engenheiro de minas, o francês Jules Henri Fayol ${ }^{1}$, por meio da publicação do trabalho: "Administration industrielle et générale - prévoyance organisation - commandement, coordination - contrôle", com a conceituação de que a garantia da eficiência das organizações estava na sua estruturação; seu olhar centrava-se no gerenciamento da produção, definindo princípios administrativos, como: "unidade de comando", "hierarquia", "divisão do trabalho" e "autoridade e responsabilidade", entre outros. Também foi de Fayol a institucionalização das funções básicas da administração, de: "planejar", "organizar", "coordenar", "comandar" $e$ "controlar" (FAYOL, 1990, p. 26). Para o autor, a administração é uma função dividida "entre a cabeça e os membros do corpo social", não sendo condição de benefício ou obrigação pessoal da chefia da empresa e não deve ser confundida com a direção, a quem cabe garantir o desenvolvimento de todas as funções essenciais, bem como a condução da organização visando à consecução dos seus objetivos com o máximo de vantagens em face dos recursos disponíveis. De acordo com Chiavenato (1979, p. 105), os "modelos administrativos Taylor-Fayol correspondem à divisão mecânica do trabalho, em que o parcelamento de tarefas é a mola do sistema. Daí ser importante nesse sistema que o operário saiba muito a respeito de pouca coisa".

Posteriormente, na década de 1930, surge a Teoria das Relações Humanas (MAYO, 1933), com base em experiências realizadas pelo psicólogo australiano George Elton Mayo, na fábrica da Western Electric em Hawthorne. As investigações contemplaram condições variadas e estruturadas de trabalho, que incorporaram, na área da análise das organizações, estudos do contexto organizacional e importância para os fatores psicológicos e sociais. É o início da valorização das relações sociais informais no âmbito das organizações.

Responsável pelo avanço e transposição da teoria da administração à sociologia da organização, Max Weber (1978) identificou algumas fragilidades nas Teorias Clássica e das Relações Humanas, especialmente quanto à necessidade da gestão, de certa forma "impessoal" e "racional", passando sua Teoria a ser decisiva nos estudos de autoridade nas organizações. Weber definiu os parâmetros teóricos da burocracia ${ }^{2}$ e as características das organizações burocráticas, com base numa concepção "ideal”, num contexto do processo de estruturação do capitalismo pelo

1 Para Fayol (1990, p. 19): “A administração constitui fator de grande importância na direção dos negócios: de todos os negócios, grandes ou pequenos, industriais, comerciais, políticos, religiosos ou até de outra qualquer índole". Para aprofundamento na teoria administrativa do autor, também conhecida como fayolismo, consultar o livro Administração industrial e geral: previsão, organização, comando, coordenação, controle / Henry Fayol 10. ed. - São Paulo: Atlas, 1990, onde Fayol expõe as ideias de como a administração deveria ser exercida.

2 De acordo com Tragtenberg (1974, p. 139): “Weber estudou a burocracia porque via na sua expansão no sistema social o maior perigo a homem. Estudou-a para criar os mecanismos de defesa ante a burocracia. O que significa burocracia para Weber? A burocracia para ele é um tipo de poder. Burocracia é igual à organização. É um sistema racional em que a divisão de trabalho se dá racionalmente com vista a fins. A ação racional burocrática é a coerência da relação de meios e fins visados. Assim, para Weber a burocracia implica predomínio do formalismo, de existência de normas escritas, estrutura hierárquica, divisão horizontal e vertical de trabalho e impessoabilidade no recrutamento dos quadros". 
domínio das organizações industriais modernas. Segundo o entendimento e definições de Weber (1982, p. 229), o funcionamento da burocracia moderna "rege o princípio de áreas de jurisdição fixas e oficiais, ordenadas de acordo com regulamentos, ou seja, por leis ou normas administrativas". Em análise crítica da realidade social, Pedro Demo (1987) enfatiza que "a Sociologia significa o tratamento teórico e prático da desigualdade social", ao mesmo tempo, considera que "as colocações sociológicas precisam ser vistas naquilo que temos de mais quotidiano: na relação familiar, na maneira de divertir-se, na burocracia que nos cerca, no imposto de renda, no relacionamento com a empregada doméstica, na educação que fazemos ou impomos, na vida profissional etc." (DEMO, 1987, p. 25).

Nesses recortes de referências relativamente à conjuntura das organizações, sobressaem os autores Gibson Burrel e Gareth Morgan que, no ano de 1979, alcançaram significativo êxito com o lançamento do livro "Sociological Paradigms and Organizational Analysis", o qual, mesmo não sendo um trabalho inteiramente dedicado à epistemologia, avança cientificamente e aprofunda a discussão paradigmática inspirada especialmente na sociologia e promove insuperável contribuição sobre fundamentos da produção científica no campo da análise organizacional. Burrell e Morgan (1979) apresentaram a concepção de que o debate das teorias sociais de análise ocorre em espaço definido por quatro paradigmas sociológicos (humanista radical, estruturalista radical, interpretativo e funcionalista) com base em diferentes conjuntos de suposições metateóricas, mutuamente excludentes, com tese central de que todas as teorias das organizações têm fundamento numa filosofia de ciência e numa teoria de sociedade, a partir das perspectivas de natureza: ontológica, epistemológica, humana e metodológica.

Ainda, vale ressaltar, nestas considerações, estudos organizacionais historicamente efetivados com base nas ciências da administração que avançaram nos Estados Unidos na década de 50 e na Europa, entre as décadas de 70 e 80 do século XX, com a incorporação de conhecimentos das ciências sociais, especialmente da sociologia e da psicologia social, para a construção de princípios da "ciência da Administração Educacional" com base em conceitos abrangentes, que vieram valorizar estudos da escola como organização, elevando-a para novos paradigmas mais próximos da escola como organização educativa. Em sintonia com essa conjuntura e apoiado em investigação realizada na escola secundária portuguesa, Lima $^{3}$ (1992) constrói um quadro teórico para as organizações educativas, com respaldo nos modelos organizacionais analíticos/interpretativos. Para Costa (1996, p. 23), os mencionados novos paradigmas consistem "em novas concepções teóricas sobre organização e administração escolar e em novos posicionamentos metodológicos que, rejeitando o 'positivismo vigente nas ciências sociais', afirmam, em alternativa, perspectivas de análise de feição 'interpretativa' e 'crítica'". A seguir, são apresentados alguns conceitos quanto à forma de estruturação das organizações.

\section{A ESTRUTURA DAS ORGANIZAÇÕES}

Em consonância com um contexto global, importa considerar que os referenciais teóricos sobre a estruturação das organizações, predominantemente, são apoiados em análises que buscam o entendimento da forma como elas funcionam. Nessa perspectiva, no tocante às formas de coordenação dos serviços e da divisão do trabalho, numa concepção de como se realizam as

Para ampliar esse conhecimento, ver o livro de Licínio Lima: A Escola como Organização e a Participação na Organização Escolar. Braga: Universidade do Minho, Instituto de Educação, 1992. 
atividades e/ou tarefas, pode-se encontrar, nas conceituações apresentadas no trabalho clássico "Estrutura e Dinâmica das Organizações" de Henry Mintzberg (1995), uma base original. Entende o autor que são elementos principais de coesão da estrutura no ordenamento do trabalho: "o ajustamento mútuo", instrumento de coordenação apoiado em encaminhamentos de comunicações informais, muito próprios para organizações simples; "a supervisão directa", instrumento que credencia um indivíduo a ficar responsável e/ou responder pela atuação de um grupo ou equipe de pessoas; "a estandardização dos processos de trabalho", que ocorre pela uniformização e padronização da forma de trabalho; "a estandardização dos resultados", que acontece pela definição de padrões a serem obtidos; e "a estandardização das qualificações", que se realiza pelas exigências de qualificação e conhecimentos das pessoas responsáveis pela operacionalização do trabalho.

Em regra geral, as realidades administrativas indicam que quanto maior for a organização, mais complexa ela é, exigindo num crescente mais unidades de gestão e, em consequência, o surgimento de hierarquizações de autoridade. De acordo com Mintzberg (1995), esse contexto se concretiza a partir de diferentes fluxos que percorrem a organização e podem ser representados por 5 (cinco) componentes: centro operacional, linha hierárquica, tecnoestrutura, pessoal de apoio (funções logísticas) e vértice estratégico, conforme o esquema ${ }^{4}$, apresentado na figura 1.

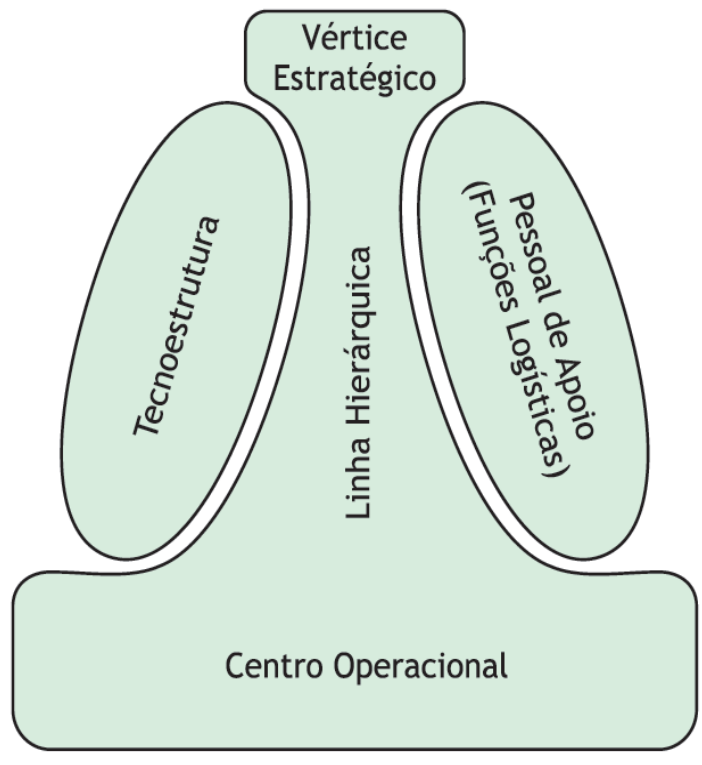

Figura 1. Os cinco componentes básicos da organização definidos por Henry Mintzberg. Fonte: Mintzberg (1995, p. 38).

São características desses componentes: a) Centro Operacional - compreende todos os membros operacionais que executam o trabalho básico relativo à produção de bens e de serviços e, entre os demais elementos estruturantes, é aquele em que, normalmente, a estandardização ocorre em maior grau; b) Vértice Estratégico - situado no plano superior da extremidade da organização, congrega os membros dirigentes de maior responsabilidade global da organização.

$4 \quad$ Conforme o entendimento de Mintzberg (1995, p. 39), relativamente ao esquema, cabe destaque o aspecto de "um vértice estratégico pequeno ligado por uma linha hierárquica poderosa a um centro operacional grande e plano. As três partes da organização são apresentadas numa seqüência contínua para indicar que se relacionam entre si, fundamentalmente, através de uma linha única de autoridade formal. A tecnoestrutura e as funções de apoio são destacadas, cada uma no seu lado, para indicar que se encontram separadas da linha única de autoridade formal, e que só indirectamente influenciam o centro operacional". 
No caso das instituições escolares, compreendem os diretores-gerais, reitores e outros cujos encargos tenham influência geral. Nesse contexto, se incluem os membros de colegiados superiores e funcionários diretamente vinculados aos quadros dirigentes; c) Linha Hierárquica atua no espaço formal da ligação do vértice estratégico com o centro operacional, estabelecendo uma cadeia de quadros e/ou níveis de autoridade numa linha decrescente. Na prática, as organizações necessitam de estruturar, na linha hierárquica, um número de gestores compatível com o quantitativo de operacionais que cada dirigente possa vir a supervisionar. No entendimento de Mintzberg (1995, p. 47), é desse modo que se "cria uma hierarquia organizacional, dando a um supervisor de primeiro nivel, responsabilidade por um certo número de operacionais, formando assim uma unidade organizacional básica"; e acrescenta o autor: "depois confia-se a um outro quadro a responsabilidade por um conjunto de unidades para formar uma unidade de nível mais elevado, e assim por diante até que todas as unidades agrupadas acabam por formar a organização no seu conjunto, sob a direcção de um único gestor no vértice estratégico - o director-geral"; d) Tecnoestrutura - é o espaço dos analistas e pessoal burocrático de apoio que, separados da sequência de atividades operacionais, atuam na formação dos operacionais, na concepção e no planejamento da organização, influenciando, assim, na eficácia da realização do trabalho dos outros; e, e) o Pessoal de Apoio (Funções Logísticas) - constituído de unidades especializadas que atuam de forma autônoma do centro operacional da organização, absorvendo algumas atividades e/ou serviços específicos de apoio não incluídos nos procedimentos do trabalho operacional.

Baseado nessas referências organizacionais e análises de formas de tomada de decisão e, ainda, em concepções de poder, Mintzberg (1995) concluiu que as organizações ajustam-se a 5 (cinco) tipos de configurações estruturais: 1) A Estrutura Simples - que tem como principal característica não ser elaborada e de frágil tecnoestrutura, sendo comum nas organizações pequenas e novas. Nessa configuração, a supervisão direta é o principal instrumento de coordenação, a tomada de decisão é centralizada em uma única pessoa (dirigente máximo) e não existe grande padronização, o que viabiliza decisões ágeis. O fluxo de trabalho se apresenta flexível, cabendo, naturalmente, ao diretor-geral a amplitude do controle sobre os membros da organização, o que conduz o vértice estratégico à posição principal da estrutura; b) A Burocracia Mecanicista - apresenta, como principal instrumento de coordenação, a padronização dos processos de trabalho. São peculiaridades da Burocracia Mecanicista: unidades operacionais grandes, comportamentos no centro operacional muito formalizados e especializados nas dimensões horizontal e vertical, atividades repetitivas, planejamento do trabalho, tarefas agrupadas com base em funções, inúmeros regulamentos e normatização abrangendo toda a organização, limitada descentralização horizontal e centralização vertical do poder decisório. Na concepção de Weber (1997, p. 39), em um Estado moderno, “o verdadeiro poder está necessária e inevitavelmente nas mãos da burocracia, e não se exerce por meio de discursos parlamentares nem por falas de monarcas, mas sim, mediante a condução da administração, na rotina do dia-adia"; c) A Burocracia Profissional - apresenta como aspecto de maior importância de coordenação das atividades a padronização das qualificações, com parâmetro na formação, especialização, socialização e descentralização vertical e horizontal. Profissionais habilitados são selecionados para integrar o centro operacional, com relevante condição de independência no seu próprio trabalho, abrindo espaço na dimensão vertical para a atividade dos operacionais, especializada na dimensão horizontal. Semelhantemente à Burocracia Mecanicista, a coordenação da estrutura da organização profissional é fundamentalmente burocrática, garantida por padrões e métodos que estabelecem, previamente, o que deve ser executado, sendo que a primeira privilegia a natureza 
hierárquica da autoridade, enquanto a Burocracia Profissional prioriza a natureza profissional do poder da competência; d) A Estrutura Divisionalizada - caracteriza-se mais como um conjunto de organizações semiautônomas chamadas divisões, coordenadas por uma estrutura central (sede), do que como uma organização homogênea. No agrupamento, não se processa trâmite do vértice estratégico ao centro operacional como nas outras configurações, porquanto cada divisão tem a sua própria estrutura somada e sobreposta às demais. As relações estruturais se concentram entre o vértice estratégico e o vértice da linha hierárquica, entre a sede e as divisões. São indicadores da Estrutura Divisionalizada: padronização de resultados, descentralização, sistema de controle de desempenho, necessidade de poder dos quadros intermediários e organização de considerável amplitude. Na Estrutura Divisionalizada, as ações desenvolvidas na sede e nas divisões têm contextos de poder diferentes, e na circulação de comunicações e decisões, entre esses 2 (dois) níveis, deve prevalecer a natureza formal. Segundo Mintzberg (1995, p. 456), talvez "a Estrutura Divisionalizada pura, que comporta muito poucas interdependências, seja realmente um <tipo ideal>, um tipo que pode ser aproximado mas nunca plenamente atingido"; e, e) A Adhocracia entendida como organizações temporárias de configuração complexa e dinâmica, pouco estruturada, voltada para o desenvolvimento de forças tarefas, equipes de projetos e de atividades de inovação, por meio da montagem de unidades funcionais de especialistas, tem o ajustamento mútuo como maior mecanismo de coordenação, recusando qualquer forma de padronização. A Adhocraria, entre as configurações estruturais, é aquela caracterizada como de menor afinidade com os conceitos clássicos da administração, priorizando a formação de equipes multidisciplinares por projeto para o aproveitamento máximo da capacidade dos peritos, independentemente de qualquer arranjo organizacional. Na Adhocraria, no entendimento de Mintzberg (1995, p. 461), os especialistas estão "repartidos em toda a estrutura, nas funções de apoio e na hierarquia, assim como no centro operacional. Portanto, muito mais do que uma concentração de poder no centro operacional, temos uma distribuição mais equitativa do poder em todas as partes da organização". No próximo item, serão conhecidos alguns parâmetros da organização instituto federal.

\section{OS INSTITUTOS FEDERAIS}

Criados no Brasil pela Lei no 11.892, de 29 de dezembro de 2008, a partir da transformação e/ou integração de entidades educacionais federais centenárias: Escolas Técnicas e Centros de Educação Tecnológica (Cefet), os Institutos Federais (IF), de acordo com o art. 2o da referida lei: "são instituições de educação superior, básica e profissional, pluricurriculares e multicampi, especializados na oferta de educação profissional e tecnológica nas diferentes modalidades de ensino". De acordo com Pacheco, Pereira, Silva e Vidor (2011, p. 94): "a lei estabelece uma estrutura multicampi, reafirmando a vocação regional dos Institutos Federais e dotando os campi de um grau de autonomia mais ampla do que aquela gozada por seus congêneres das universidades". Estabelece-se, assim, a configuração de uma organização educativa (IF) composta de organizações escolares (FERNANDES, 2008), em substituição à estruturação linear das instituições educacionais reformadas. Em termos de padrões de estrutura organizativa, tomando como referência os princípios em apreciação, a configuração estrutural do Instituto Federal, considerando uma aproximação de tipo ideal weberiano, de imagem que possa compreender um sistema organizacional complexo, conduz as características de análise para o escopo de uma "Estrutura Divisionalizada", tendo a reitoria como órgão executivo central do Instituto, a função de coordenar e supervisionar todos os campi (Unidades Escolares dotadas de autonomia 
administrativa e financeira), criados para o atendimento à população dos seus respectivos territórios, numa perspectiva de desenvolvimento social sustentável e de redução das desigualdades regionais.

Uma estrutura matricial, derivada da autonomia multicampi, conduz a ambiguidades na ação da política institucional pela não garantia de sintonia entre as diretivas da reitoria e dos campi e/ou pela intervenção de órgãos sistêmicos da sede na ação das unidades escolares; essas situações caracterizam, ao mesmo tempo, formas de configurações híbridas em face do funcionamento dos campi onde os operacionais, respaldados na formação profissional externa e qualificações, produzem forças que conduzem à estruturação da organização na direção de uma Burocracia Profissional.

Efetivamente, com a Lei no 11.892/2008, o governo federal procedeu a uma profunda transformação na rede federal, situação provocativa do desencadeamento de uma mudança cultural pela criação de "condições e espaço para a construção de novas formas de organização, novas possibilidades de acção, novas relações de poder" (TORRES, 2011, p. 5). Na perspectiva de Gareth Morgan (2002, p. 164-165): "o desafio de criar novas formas de organização e de administração é em grande parte o desafio de gerar uma mudança cultural" e, avançando na questão, explicita: "a criação de determinada cultura corporativa não consiste apenas em inventar novos lemas ou adquirir um novo líder. Ela consiste em inventar um novo modo de vida". Seguindo o mesmo raciocínio, entende Licínio Lima (2009, p. 48) que não é fácil mudar estruturas organizacionais, "afastar o poder enquistado, e resistente, da burocracia; nem é fácil substituir uma estrutura administrativa por outra, ou reformá-la, e muito menos garantir que a segunda não venha, bem cedo, a recuperar os padrões burocráticos da primeira, weberianamente universais".

Num contexto de esfera pública e ordenação legal, de ineditismo organizacional, de hibridismo, de uma administração multicampi com demandas educacionais multiníveis, a cada Instituto Federal coube o desafio próprio de se estruturar, numa perspectiva subliminar de configuração de sistema de rede federal de educação profissional, científica e tecnológica. De acordo com a compreensão de Pacheco e Silva (2009, p. 11), a gestão de cada Instituto Federal e da rede que formam "assume um caráter sistêmico que exige o reconhecimento da autonomia de cada unidade, bem como a necessidade de trabalho permanente em prol do equilíbrio estrutural entre os campi de um mesmo instituto e entre os institutos".

Essa referida autonomia multicampi legalmente estabelecida, para ser efetivada num contexto de uma "convivência relativa de poder" (FERNANDES, 2015, p. 422) entre o reitor e os diretores-gerais dos Campi, também associada a medidas de descentralização e desconcentração de poder, na realidade do funcionamento das ações institucionais, enfrenta dificuldades de efetivação, situação que fortalece o entendimento de Lima $(1998$, p. 68) de que "as instituições não mudam apenas, nem sobretudo, por força das mudanças jurídico-normativas, por mais relevantes que estas sejam". Por outro lado, o modelo teórico da burocracia profissional peculiar à cultura universitária não espelha a proposição organizacional da autonomia multicampi legalmente definida para o Instituto Federal. Na concepção de João Barroso (2005, p. 108), o conceito de autonomia ${ }^{5}$ está etimologicamente ligado à ideia de "auto-governo, isto é, à faculdade

5 Entende o autor que a autonomia "é um conceito relacional (somos sempre autónomos de alguém ou de alguma coisa) pelo que a sua acção se exerce sempre num contexto de interdependências e num sistema de relações. A autonomia é também um conceito que exprime sempre um certo grau de relatividade: somos mais, ou menos, 
que os indivíduos (ou as organizações) têm de se regerem por regras próprias. Contudo, se a autonomia pressupõe a liberdade (e capacidade) de decidir, ela não se confunde com a 'independência". . Considera ainda o autor que a "autonomia da escola" não deve ser restrita a uma dimensão legal, e alerta para a sua dimensão "ética, social e política", que, no caso de um serviço público de educação, "deve contribuir para construção de um 'bem comum local' que garanta, em condições de igualdade, equidade e eficácia, a educação de todas as crianças e jovens que freqüentam uma determinada escola" (BARROSO, 2005, p. 110).

Em trabalho de análise sobre as mudanças ocorridas no campo da organização escolar e das políticas educativas na Europa e, mais especificamente, em Portugal, o autor, relacionando a importância do desenvolvimento da teoria dos sistemas no domínio educacional ao conceito de regulação "mais flexível na definição dos processos e rígida na avaliação da eficiência e eficácia dos resultados" (BARROSO, 2005, p. 63), no controle de componentes autônomos, mas interdependentes, considera autêntico o processo de intervenção do Estado como regulador de instabilidades e descontroles, no tocante à manutenção de normalidade e eficiente funcionamento de suas unidades e/ou organizações executivas.

Tomando, ainda, por base estudos sobre regulação política no continente europeu, na perspectiva de instrumento de governo para mudanças organizacionais dos sistemas de ensino superior, vislumbra Magalhães (2010, p. 62) que, nessas situações, a autonomia institucional tem "como pressuposto que, assim, as instituições desenvolvem a capacidade de responder mais eficiente e eficazmente às alterações do meio ambiente organizacional". Por outro lado, sobre questões referentes à autonomia da escola, Lima (2013, p. 67) adverte que, apesar de ser um discurso corrente dos governos, as reformas na educação pública, em muitos países, "embora com impactos variados e apropriações diversas, têm, de acordo com a investigação disponível, destacado um vasto conjunto de dimensões, entre as quais: centralização da formulação das políticas educativas e dos processos de decisão sobre o currículo e a avaliação".

No Brasil, em virtude dos rankings nacionais a que se submetem ou devido a outras variadas formas de avaliação governamental, invariavelmente recai sobre a organização e administração da instituição de ensino pública, a responsabilização pelos resultados e escores alcançados nas avaliações, não sendo levado em conta, na quase totalidade das vezes, as variáveis de autonomia, estruturação e especificidades das unidades educacionais. No próximo e último tópico deste artigo, é considerada a interface de modelagem organizacional do Instituto Federal com os conceitos da Estrutura Divisionalizada.

\section{CONSIDERAÇÕES FINAIS}

Ao determinar normativamente para o Instituto Federal (IF) um padrão diverso da estruturação do tipo funcional de hierarquização verticalizada, admitido até em alguns casos, já sob formas pós-burocráticas e/ou com a incorporação de elementos de "hiperburocratização" (LIMA, 2012), vivenciada nos transformados Centros Federais de Educação Tecnológica e no funcionamento das universidades, o governo brasileiro cria uma organização multifacetada e

autónomos; podemos ser autónomos em relação a umas coisas e não o ser em relação a outras. A autonomia é, por isso, uma maneira de gerir, orientar, as diversas dependências em que os indivíduos e os grupos se encontram no seu meio biológico ou social, de acordo com as suas próprias leis" (BARROSO, 2005, p. 108). 
híbrida e transfere a cada IF a responsabilidade pelos desafios da constituição da nova institucionalidade, inclusive sua afirmação perante a burocracia estatal nacional, habituada às realidades do modelo das instituições de ensino superior universitárias. Na perspectiva de WOOD JR (2010, p. 242), "a condição híbrida contém um forte componente de indeterminação, pois pode desestabilizar os referenciais existentes e turvar as distinções entre cultura local e cultura corporativa".

Aspectos peculiares da supramencionada organização educativa, na realidade, concorrem para que sua estruturação não fique restrita a perspectivas e conceituações de um padrão teórico, devido à concomitância de componentes vinculados à colegialidade, à burocracia, à autonomia dos professores e às ambiguidades, em que se embasa e se desenvolve a ação organizacional e são tomadas as decisões. Essa situação vai além das características definidas por Mintzberg (1995) como "burocracia profissional" para as universidades, relacionadas a uma estrutura democrática em que profissionais controlam o trabalho e decisões administrativas e descentralizadas nas dimensões vertical e horizontal, além da convivência de hierarquias administrativas paralelas, uma na direção ascendente, mais democrática; outra na direção descendente, de característica mecanicista, de controle das funções de apoio.

A forma de semigovernação, de arranjo de rede, de funcionamento com personalidade jurídica e unidade de gestão próprias, pelos campi, integrados por acoplamentos frouxos com a reitoria, numa concepção estrutural de "federação interdependente de campi" (FERNANDES, 2015, p. 391), também natureza de uma concepção de subunidades organizacionais, pela dependência da sede, juridicamente detentora central da identidade institucional, aproxima, teoricamente, a imagem organizacional do Instituto Federal da modelagem de Estrutura Divisionalizada considerada por Mintzberg (1995, p. 414), "muitas vezes o produto, não da <descentralização> de uma Burocracia Mecanicista que opera em numerosos mercados, mas da centralização de um conjunto de organizações independentes" e que se consolidam "numa só <federação> que adopta a configuração de Estrutura Divisionalizada, cedendo parte dos seus poderes à nova sede central" (MINTZBERG, 1995, p. 415).

Essa forma de estruturação divisionalizada evidencia-se como aquela que melhor viabiliza a coordenação regular do funcionamento de um elevado número de campi pelo órgão executivo (reitoria) do Instituto, com o recurso ao princípio da descentralização de poderes e delegação de competência, do reitor para os diretores-gerais dos campi. Soma-se à conjuntura, a condição de que cada campus tem sua própria conformação administrativa e acadêmica de ensino, pesquisa e extensão, ou seja, uma estrutura com todos os componentes básicos da organização, do vértice estratégico no topo ao centro operacional na base.

O apelo à divisionalização organizacional no Instituto Federal também surge concomitante às tomadas de decisões dos colegiados superiores criados por lei, ou seja, o Conselho Superior e o Colégio de Dirigentes, bem como das regulamentações expedidas pela reitoria, passíveis de variados encaminhamentos e interpretações pelas direções dos campi. No entendimento de Costa (2003, p. 1326), "a existência de desarticulação, de conflitualidade, de situações anárquicas e artificiais, a instabilidade e a imprevisibilidade que grassam no seio das organizações devem ser motivo para se procurar novas formas de organização".

Não restam dúvidas de que a análise exploratória apresentada neste documento, pertencente ao campo teórico de modelos organizacionais emergentes, deve ser entendida como 
estímulo para outros e novos estudos que deverão alcançar patamares mais elevados do conhecimento.

\section{REFERÊNCIAS}

1. BARROSO, João. Políticas Educativas e Organização Escolar. Lisboa: Universidade Aberta, 2005.

2. BRASIL. Lei no 11.892, de 29 de dezembro de 2008. Disponível em: https://www.planalto.gov.br/ccivil_03/_ato2007-2010/2008/lei/l11892.htm. Acesso em: 10 abr.2016.

3. BURRELL, Gibson e MORGAN, Gareth. Sociological Paradigms and Organisational Analysis. Londres: Heinemann Educational Books Ltd, 1979.

4. CHIAVENATO, Idalberto. Teoria geral da administração - São Paulo: McGraw-Hill do Brasil, 1979.

5. COSTA, Jorge A. Imagens Organizacionais da Escola - Porto: Edições ASA, 1996.

6. COSTA, Jorge A. Projectos educativos das escolas: um contributo para a sua (des)construção. Revista Educação \& Sociedade, Campinas, ISSN 0101-7330, v. 24, n. 85, p. 1319-1340, 2003.

7. DEMO, Pedro. Sociologia: uma introdução crítica - 2a ed. São Paulo: Atlas, 1987.

8. FAYOL, Henri. Administração industrial e geral: previsão, organização, comando, coordenação, controle; tradução de Irene de Bojano e Mário de Souza - 10. ed. São Paulo: Atlas, 1990.

9. FERNANDES, Francisco C. M. Novo design para a Rede Federal de Educação Tecnológica. Revista Holos, Natal, ISSN 1807 - 1600, v. 3, p. 56-66, 2008.

10. FERNANDES, Francisco C.M. Racionalidades e Ambiguidades da Organização Instituto Federal: o caso do Rio Grande do Norte. Braga: Universidade do Minho, Instituto de Educação, 2015.

11. LIMA, Licínio C. A Escola como Organização e a Participação na Organização Escolar. Braga: Universidade do Minho, Instituto de Educação, 1992.

12. LIMA, Licínio C. Universidade Portuguesa: Notas sobre a Crise Institucional. In MOROSINI, Marília Costa (org). MERCOSUL/MERCOSUR: políticas e ações universitárias. Campinas: Autores Associados, 1998, p. 65-76.

13. LIMA, Licínio C. Organização escolar e democracia radical: Paulo Freire e a governação democrática da escola pública - 4. ed. - São Paulo: Cortez: Instituto Paulo Freire, 2009.

14. LIMA, Licínio C. Elementos de hiperburocratização da administração educacional. In LUCENA, Carlos e SILVA JÚNIOR, J. dos R. (orgs). Trabalho e educação no século XXI: experiências internacionais. São Paulo: Xamã, 2012, p. 129-158.

15. LIMA, Licínio C. Diretor(a) de escola pública: unipessoalidade e concentração do poder no quadro de uma relação subordinada. In PERONI, Vera Maria Vidal (org). Redefinições das fronteiras entre o público e o privado: implicações para a democratização da educação. Brasília: Liber Livro, 2013, p. 58-81.

16. MAGALHÃES, António M. Os modelos emergentes de regulação política e a governação do Ensino Superior na Europa. In TEODORO, António (org). A Educação Superior no Espaço Iberoamericano. Do Elitismo à Transnacionalização. Lisboa: Edições Universitárias Lusófonas, 
2010, p. 37-67.

17. MAYO, Elton. The Human Problems of an Industrial Civilization. New York: The Macmillan Company, 1933.

18. MINTZBERG, Henry. Estrutura e Dinâmica das Organizações; tradução de Amélia Salavista Brooker - revisão técnica de António Caetano. Lisboa: Publicações Dom Quixote, 1995.

19. MORGAN, Gareth. Imagens da organização: edição executiva; tradução Geni G. Goldschmidt. - 2. ed. - 4a reimpressão. São Paulo: Atlas, 2002.

20. PACHECO, Eliezer e SILVA, Caetana J. R. Institutos Federais: um futuro por armar. In SILVA, Caetana J. R. (org). Institutos Federais - Lei 11.892, de 29/11/2008: comentários e reflexões. Natal: Editora do IFRN, 2009, p. 7-11.

21. PACHECO, Eliezer; PEREIRA, Luiz A. C.; SILVA, Caetana J. R. e VIDOR, Alexandre Martins. Institutos Federais: Lei 11.892 de 29/11/2008 - comentários e reflexões. In PACHECO, Eliezer (org). Institutos Federais: uma revolução na educação profissional e tecnológica. São Paulo: Editora Moderna, 2011, p. 47-113.

22. TAYLOR, Frederick W. Princípios de administração científica; tradução de Arlindo Vieira Ramos - 7. ed. São Paulo: Atlas, 1985.

23. TORRES, Leonor L. A cultura da escola perante a influência da comunidade: um estudo de caso numa escola portuguesa. Revista Ibero-americana de Educação - ISSN 1681-5653, n. 56/1, p. 1-13, 2011. Disponível em: http://www.rieoei.org/deloslectores/3907Lima.pdf. Acesso em: 31 mar.2016.

24. TRAGtenBerg, Maurício. Burocracia e ideologia. São Paulo: Ática, 1974.

25. WEBER, Max. Os Fundamentos da Organização Burocrática: uma construção do tipo ideal. In CAMPOS, Edmundo (organização e tradução). Sociologia da Burocracia, 4. ed. - Rio de Janeiro: Zahar, 1978, p. 15-28.

26. WEBER, Max. Ensaios de Sociologia; tradução de Waltensir Dutra - revisão técnica de Fernando Henrique Cardoso - 5. ed. - Rio de Janeiro: LTC Editora, 1982.

27. WEBER, Max. Os Economistas - Textos Selecionados; traduções de Maurício Tragtenberg, Waltensir Dutra, Calógeras A. Pajuaba, M. Irene de Q. F. Szmrecsányi e Tamás J. M. K. Szmrecsányi - São Paulo: Nova Cultural, 1997.

28. WOOD JR, Thomaz. Organizações híbridas. Revista de Administração de Empresas, São Paulo ISSN 0034-7590, v. 50, n. 2, p. 241-247, 2010. 